\title{
Synthesis of a low-bandgap polymer bearing side groups containing phenoxy radicals
}

\author{
Yu Innami, ${ }^{1}$ Rafaël H. L. Kiebooms, ${ }^{2}$ Tamotsu Koyano, ${ }^{1,3}$ Masaaki \\ Ichinohe ${ }^{4}$ Satoshi Ohkawa, ${ }^{1}$ Kohsuke Kawabata, ${ }^{1}$ Masataka Kawamatsu, ${ }^{1}$ \\ Kiyoto Matsuishi, ${ }^{1}$ and Hiromasa Goto ${ }^{1, *}$ \\ ${ }^{1}$ Institute of Materials Science, Graduate School of Pure and Applied Sciences, \\ University of Tsukuba, Tsukuba, Ibaraki, 305-8573, Japan \\ ${ }^{2}$ European Patent Office, Bayerstr 34, 80335 Munich, Germany \\ ${ }^{3}$ Cryogenic Center, University of Tsukuba, Tsukuba, Ibaraki, 305-8577, Japan \\ ${ }^{4}$ Department of Chemistry, Graduate School of Pure and Applied Sciences, University \\ of Tsukuba, Tsukuba, Ibaraki, 305-8571, Japan
}

* Author to whom correspondence should be addressed; H. Goto, e-mail: gotoh@ims.tsukuba.ac.jp; tel.: +81-29-853-5128; fax: +81-29-853-4490.

\begin{abstract}
Poly(isothianaphthene methine) bearing di-tert-butylphenoxide in the side chain was prepared by reacting isothianaphthene and 3,5-di-tert-butyl-4-hydroxybenzaldehyde in the presence of $\mathrm{POCl}_{3}$. A reference polymer with no hydroxy group in the side chain was also synthesized. Both polymers are characterized by a low-bandgap with value of ca. $1.3 \mathrm{eV}$ obtained by optical absorption spectroscopy, and ca. $1.7 \mathrm{eV}$ estimated from an electrochemical method. After treatment with $\mathrm{PbO}_{2}$ as an oxidizer, phenoxy radicals were generated by oxidation in the polymer side groups. Optical absorption measurements and electron spin resonance (ESR) showed a characteristic signal due to phenoxy radicals. Magnetic properties of the polymer were examined with ESR and superconducting quantum interference device (SQUID) measurements. The results suggested that the polymer shows paramagnetic behavior.
\end{abstract}

Keywords: $\pi$-conjugated polymer; electron spin resonance (ESR); isothianaphthene (ITN); low-bandgap; radical 


\section{Introduction}

$\pi$-conjugated molecules have been studied widely for electronic materials and optical devices [1-10]. A low-bandgap polymer has a notably strong interaction between electrons in the polymer backbone. Applications as transparent electrodes or electrochromic materials have been developed. Specifically, among low-bandgap polymers, isothianaphthene-based polymers have remarkable electronic and optical properties [11-19].

Polymer-based magnetic materials have attracted interest in many fields [20-22]. Magnetism in polymers originated from radicals shows characteristic electrochemical or optical properties. Recent studies have reported synthesis and properties of functional radical polymers and devices using radical compounds such as radical batteries and radical light-emitting diodes [23-26]. We attempt a combination of a low-bandgap polymer based on polyisothianaphtene and stable radial groups for creation of lowbandgap $\pi$-conjugated radical polymers.

\section{Experimental}

Technique

Fourier transform Infrared spectra (FT-IR) of polymers were taken with a JASCO FTIR 300 spectrometer by the KBr method. Fourier transform Raman (FT-Raman) spectra were obtained by using a Nicolet NXR FT-Raman spectrometer with $1064 \mathrm{~nm}$ excitation wavelength. Ultraviolet-visible (UV-Vis) absorption spectroscopy measurements were carried out at room temperature by using a HITACHI U-3500 spectrometer with a quartz cell. Cyclic voltammetry (CV) measurements were carried out by repeated potential cycling using an ECO CHEMIE $\mu$ AUTOLAB TYPE III. The three electrode system consists of a platinum disc working electrode, an $\mathrm{Ag} / \mathrm{Ag}^{+}$ reference electrode, and a platinum wire counter electrode. CV measurements were performed using electrolytic acetonitrile solutions containing $0.1 \mathrm{M}$ of tetrabutylammonium perchlorate at a scan rate of $50 \mathrm{mV} / \mathrm{s}$. Molecular weights of the polymers were determined by gel permeation chromatography (GPC) using a JASCO HPLC 870-UV detector, with tetrahydrofuran (THF) as the solvent, with the instrument calibrated with polystyrene standards. ESR measurement of the polymer in solid state was carried out with a JEOL JES TE-200 spectrometer and a Bruker EMXPlus9.5/2.7 spectrometer. The polymer was packed into a $5 \mathrm{~mm}$ quartz tube. The sample tube was evacuated before sealing. The spin concentration was determined using $\mathrm{CuSO}_{4} \cdot 5 \mathrm{H}_{2} \mathrm{O}$ as the internal standard. Magnetic susceptibility measurement for the polymer was performed with a Quantum Design MPMS-3 SQUID magnetometer $( \pm 5 \mathrm{~T})$. The polymer was packed into a $5 \mathrm{~mm}$ diameter quartz cell connected to Pyrex glass tube. After evacuation, the tube was sealed for SQUID measurements. The magnetic susceptibility was measured from $2 \mathrm{~K}$ to $300 \mathrm{~K}$ under magnetic fields of 1,2 and $4 \mathrm{~T}$.

Polymer synthesis and oxidation

The isothianaphthene monomer 1,3-bis(tert-butyldimethylsilyl)isothianaphthene (1) was synthesized in three steps [27]. The synthetic routes to poly(isothianaphthene methine)s are shown in Scheme 1. A solution of isothianaphthene monomer (1) (0.363 g, 1.00 mmol) and 3,5-di-tert-butyl-4-hydroxybenzaldehyde $(0.237 \mathrm{~g}, 1.00 \mathrm{mmol})$ in 1,4dioxane $(8.00 \mathrm{~mL})$ was refluxed at $85^{\circ} \mathrm{C}$ in the presence of $\mathrm{POCl}_{3}(2.00 \mathrm{~mL})$ for $24 \mathrm{~h}$. 
Then, the solution was poured into a large amount of methanol and the precipitate was collected to obtain an indigotic blue solid followed by centrifugal separation and vacuum drying $(0.188 \mathrm{~g}, \mathrm{Y}=53.6 \%)$. The polymer (poly2) was synthesized under the same conditions used for the preparation of poly1. The isothianaphthene monomer (1) (0.090 g, $0.25 \mathrm{mmol})$ and 3,5-di-tert-butylbenzaldehyde $(0.055 \mathrm{~g}, 0.25 \mathrm{mmol})$ were dissolved in 1,4-dioxane $(2.50 \mathrm{~mL})$, and subsequently the solution was refluxed at $85{ }^{\circ} \mathrm{C}$ in the presence of $\mathrm{POCl}_{3}(0.50 \mathrm{~mL})$ for $24 \mathrm{~h}$. After work up $13.2 \mathrm{mg}$ of an indigotic blue solid was obtained $(\mathrm{Y}=16.0 \%)$. Poly1 and poly2 were subsequently neutralized with excess amount of triethylamine.

Next, a suspension of the poly1 $(0.051 \mathrm{mg})$ in toluene $(10.0 \mathrm{~mL})$ containing fresh $\mathrm{PbO}_{2}(0.5021 \mathrm{mg})$ was stirred for $20 \mathrm{~min}$ under an argon atmosphere to generate radicals at the side chains [28]. The solution was then filtered and freeze-dried under reduced pressure to yield poly1' as a polyradical. The number average molecular weights $\left(M_{\mathrm{n}}\right)$ of poly1 and poly2 were found to be 2000 and 1440, respectively; the weight average molecular weights $\left(M_{\mathrm{w}}\right)$ were 2980 and 1880, respectively, evaluated by GPC with THF as the solvent, against a polystyrene standard (Table 2). The molecular weights seem to be somewhat low because the polymers are poorly soluble in THF, and the GPC measurement thus probably provides results for only the low-weight molecular mass fraction. Therefore, the actual molecular weights of poly1 and poly 2 might be larger than the results of the GPC measurements.

\section{Results and Discussion}

\section{FT-IR and FT-Raman spectroscopy}

The FT-IR absorption spectra of poly1 and poly2 are shown in Fig. 1a. The major bands observed on FT-IR and FT-Raman spectra are listed in Table 1. The absorption band at $3431 \mathrm{~cm}^{-1}$ which corresponds to $\mathrm{O}-\mathrm{H}$ stretching was observed in poly1, while poly 2 showed no signal around $3431 \mathrm{~cm}^{-1}$. It indicates that poly 1 has $\mathrm{OH}$ groups in the side chain. Poly 1 and poly 2 showed absorption bands associated with $\mathrm{C}=\mathrm{C}$ vibration of quinonoid isothianaphthene unit at $1588 \mathrm{~cm}^{-1}$ and $1589 \mathrm{~cm}^{-1}$, respectively [16].

Fig. 1b shows the FT-Raman spectra of poly1 and poly2. FT-Raman spectroscopic studies of polyisothianaphthene and poly(isothianaphthene methine) derivatives have been reported [29-31]. The Raman bands of poly1 and poly2 were associated with vibrations of benzenoid and quinonoid isothianaphthene units. This analysis indicates that poly1 and poly2 are copolymers of the isothianaphthene and the benzaldehyde derivatives, and have benzenoid and quinonoid isothianaphthene units in the main chain.

UV-vis absorption spectroscopy

The UV-vis optical absorption spectra of poly1 (having $\mathrm{OH}$ as the substituent) and poly2 (no $\mathrm{OH}$ as the substituent) were obtained in $\mathrm{CHCl}_{3}$ solution (Fig. 2a). Both polymers show wide absorption bands in the visible range. Poly1 shows an absorption maximum $\left(\lambda_{\max }\right)$ at $673 \mathrm{~nm}$ and poly 2 at $642 \mathrm{~nm}$. From the band-edge of the spectra for these polymers, the band-edge bandgaps are estimated to be $1.3 \mathrm{eV}$ for the both polymers. 
Fig. 2b shows the UV-vis absorption spectra of poly1' (having oxyradical as the substituent) obtained from oxidation of poly1. Poly1' exhibits a characteristic peak near $460 \mathrm{~nm}$. Yoshioka et al. [32] have reported that polyacetylenes bearing 2,6-di-tertbutyl-4-phenoxy radicals have an absorption band at $495 \mathrm{~nm}$. It should be noted that the absorption band of $460 \mathrm{~nm}$ is the phenoxy radical [23-24]. Fig. 2b shows absorption spectra of poly $2_{\mathrm{PbO} 2}$ after treatment with $\mathrm{PbO}_{2}$ as a reference (no oxyradical). The absorption spectrum of poly $2_{\mathrm{PbO} 2}$, which has no phenoxy radical in the side chain, does not show the characteristic peak at $460 \mathrm{~nm}$. From these results, we conclude that the absorption spectrum of poly1' indicates the presence of phenoxy radicals.

Electrochemical measurement

Cyclic voltammetry (CV) measurements were carried out in acetonitrile solution containing $0.1 \mathrm{M}$ tetrabutylammonium perchlorate (TBAP) at a scan rate of $50 \mathrm{mV} / \mathrm{s}$. The cyclic voltammograms for poly1 and poly2 are shown in Fig. 3. An oxidation peak with an onset of $E_{\text {ox } / \text { onset }}=0.55 \mathrm{~V}$ (vs. $\mathrm{Ag} / \mathrm{Ag}^{+}$), and a reduction peak with an onset of $E_{\text {red/onset }}=-1.12 \mathrm{~V}\left(\mathrm{vs} . \mathrm{Ag} / \mathrm{Ag}^{+}\right)$were observed for poly1. Poly2 showed similar electrochemical response. The onsets of oxidation and reduction peaks for poly1 and poly2 were calibrated using $\mathrm{Fc} / \mathrm{Fc}^{+}$. The onset oxidation potential of $\mathrm{Fc} / \mathrm{Fc}^{+}$measured in the solvent was $-0.04 \mathrm{~V}$ vs. $\mathrm{Ag} / \mathrm{Ag}^{+}$, thus $E_{\text {ox/onset }}$ and $E_{\text {red/onset }}$ of poly1 and poly 2 were calibrated to add $0.04 \mathrm{~V}$ to the potentials. These results are summarized in Table 2. Li and Bonardi et al. [33-34] suggested that highest occupied molecular orbital (HOMO) and lowest unoccupied molecular orbital (LUMO) energy levels can be estimated from $\mathrm{CV}$ results. The onset of an oxidation peak (vs. $\mathrm{Fc} / \mathrm{Fc}^{+}$) was recalculated to electron volts versus vacuum level using a potential value of $-4.75 \mathrm{eV}$ [35]. In this study, the energy levels were obtained by adding 4.75 to the potentials (vs. $\mathrm{Fc} / \mathrm{Fc}^{+}$). For example, the HOMO energy $\left(E_{\mathrm{HOMO}}\right)$ and the LUMO energy $\left(E_{\mathrm{LUMO}}\right)$ of poly1 can be estimated as $E_{\mathrm{HOMO}}=-\left(E_{\mathrm{ox} / \mathrm{onset}}+4.75\right)$, and $E_{\mathrm{LUMO}}=-\left(E_{\text {red/onset }}+4.75\right)$, respectively. The bandgap $E_{\mathrm{g}}(\mathrm{CV})$ is also estimated to be $E_{\mathrm{g}}(\mathrm{CV})=E_{\mathrm{LUMO}}-\left(E_{\mathrm{HOMO}}\right)$. From these calculations $E_{\mathrm{g}}(\mathrm{CV})$ is estimated to be $1.67 \mathrm{eV}$. This bandgap $E_{\mathrm{g}}(\mathrm{CV})$ is slightly higher than the bandgap of poly1 estimated from the UV-vis optical absorption spectroscopy $\left(E_{\mathrm{g}}(\mathrm{opt})=1.32 \mathrm{eV}\right)$.

\section{Magnetic properties}

Fig. 4a shows electron spin resonance (ESR) spectra of poly1' and poly2 ${ }_{\mathrm{PbO} 2}$. Poly1' showed a signal with a $g$-value of 2.004 [36], whereas poly2 shows no characteristic signal in the ESR. According to Chen et al. [37] poly(isothianaphthene) synthesized under oxidative conditions intrinsically shows a $g$-value of 2.006 due to generation of polarons as charge carriers. This result indicates that oxidation of poly2 with $\mathrm{PbO}_{2}$ affords no charge career along the main chain. Therefore, the $g$-value of 2.004 indicates phenoxy radicals in the side chain of poly1'. The ESR spectrum of poly1' was also obtained at low temperature. Fig. $4 \mathrm{~b}$ shows the ESR spectra for poly1' at $4-90 \mathrm{~K}$. The ESR intensity increased with the decrease of temperature. Appearance of hyperfine structure-like signal at $4 \mathrm{~K}$ implies that the electron spin of phenoxy radicals interacts with hydrogen on the benzene ring or tert-butyl groups in the side chain. 
Yoshizawa et al. suggested that the magnetic susceptibility $(\chi)$ can be estimated from an ESR spectrum. The $\chi$ is given as follows:

$$
\chi=C \Delta H_{p p}^{2} I_{p p}
$$

where $\Delta H_{p p}$ is the peak-to-peak line width, $I_{p p}$ is the height of the differential curve, and $C$ is a constant which depends on the measurement conditions such as sensitivity and amplitude of the apparatus [38]. It is noted that $\chi$ theoretically depends on a temperature (T) followed the Currie-Weiss law,

$$
\chi=C_{\text {curie }} /(T-\theta)
$$

here $C_{\text {curie }}$ is the Curie constant, and $\theta$ is the Weiss constant.

The $\chi$ (estimated from $\Delta H_{p p}{ }^{2} I_{p p}$ ) vs. $T$ plots and the $\chi T$ (estimated from $\Delta H_{p p}{ }^{2} I_{p p} T$ ) vs. $T$ plots for the poly $1^{\prime}$ are shown in Fig. 5. $\chi$ decreases with the temperature. This result is observable for general magnetic materials. $\chi T$ is almost constant against temperature, indicating the polymer shows paramagnetic behavior.

Magnetic behavior of poly1' was also examined with a superconducting quantum interference device (SQUID), as shown in Fig. 6. $\chi$ value decreases with temperature, whereas $\chi T$ is almost constant. These are the same trend as these of the ESR results, suggesting the polymer show paramagnetic behavior. However, $\chi^{-1}$ vs. $T$ plots for poly1' shows $\theta<0(\theta \approx-5.0 \mathrm{~K})$. This implies poly1' might have some contents of intrachain (through the conjugated main chain) antiferromagnetic interaction.

The spin concentration of polyl' was $2 \%$ per unit cell determined by ESR spectroscopy. The low spin concentration can be due to the poor solubility of poly1' in the solvent during the radical generation process and the oxidation reaction with $\mathrm{PbO}_{2}$ was not sufficient in this experiment. Furthermore, the extinction of radicals and crosslinking of the polymer might occur after oxidation. However, the results in the present study clearly demonstrate the synthesis of low-bandgap polymers having magnetic properties.

\section{Conclusions}

Low-bandgap poly(isothianaphthene methine)s were obtained under oxidative conditions. Poly1 and poly2 showed a broad absorption band at long wavelengths in the optical absorption spectra. Phenoxy radicals in the side-chain of poly1' were generated with $\mathrm{PbO}_{2}$. The generation of the phenoxy radicals was confirmed by the UV-vis optical absorption and the ESR measurements. Although further investigation of the magnetic behavior and improvement of the synthesis to increase the radical concentration of the polymer are required, in this study we successfully synthesized low-bandgap polymers having stable radical groups. This type of polymer may be a useful material of an energy storage application (i.e., radical battery) and could be used for the development of organic magnetic-optical devices. 
Acknowledgements We would like to thank the Chemical Analysis Division of Research Facility Center for Science and Technology, and the Glass Work Shop of the University of Tsukuba. We also thank Prof. Seiji Kojima (University of Tsukuba) for kindly providing Raman spectroscopy instrumentation.

\section{References}

1. Rojo G, Agulló-López F, Campo J, Cano M, Lagunas M, Heras J (2001) Synth Met 124:201

2. Chen M, Perzon E, Robisson N, Jönsson S, Andersson M, Fahlman M, Berggren M (2004) Synth Met 146:233

3. Shi C, Wu Y, Zeng W, Xie Y, Yang K, Cao Y (2005) Macromol Chem Phys 206:1114

4. Xia J, Masaki N, Lira-Cantu M, Kim Y, Jiang K, Yanagida S (2008) J Am Chem Soc 130:1258

5. Hou J, Park M, Zhang S, Yao Y, Chen L, Li J, Yang Y (2008) Macromolecules 41:6012

6. Harpham M, Süzer Ö, Ma C, Bäuerle P, Goodson T (2009) J Am Chem Soc 131:973

7. Amrutha S R, Jayakannan M (2009) J Phys Chem B 113:5083

8. Kawabata K, Goto H (2010) Synth Met 160:2290

9. Rogojanu A, Rusu E, Dorohoi D O (2010) International Journal of Polymer Analysis and Characterization 15:210

10. Tarkuc S, Unver E, Udumb Y, Toppare L (2010) Eur Polym J 46:2199

11. Kobayashi M, Colaneri N, Boysel M, Wudl F, Heeger A (1985) J Chem Phys 82:5717

12. Quattrocchi C, Lazzaroni R, Brédas J, Kiebooms R, Vanderzande D, Gelan J, Meervelt L (1995) J Phys Chem 99:3932

13. Kiebooms R, Adriaensens P, Vanderzande D, Gelan J (1997) J Org Chem 62:1473

14. Meng H, Wudl F (2001) Macromolecules 34:1810

15. Kiebooms R, Goto H, Akagi K (2001) Synth Met 119:117

16. Kiebooms R, Goto H, Akagi K (2001) Macromolecules 34:7989

17. Liu C, Oshima K, Shimomura M, Miyauchi S (2005) J Appl Polym Sci 97:1848

18. Kim J, Qin Y, Stevens D, Kalihari V, Hillmyer M, Frisbie C (2009) J Phys Chem C 113:21928

19. Yamamoto T, Usui M, Ootsuka H, Iijima T, Fukumoto H, Sakai Y, Aramaki S, Yamamoto H, Yagi T, Tajima H, Okada T, Fukuda T, Emoto A, Ushijima H, Hasegawa M, Ohtsu H (2010) Macromol Chem Phys 211:2138

20. Xie C, Lahti P (1999) J Polym Sci Part A: Polym Chem 37:779

21. Rajca A, Wongsriratanakul J, Rajca S, Cerny R (2004) Chem Eur J 10:3144

22. Vandeleene S, Jivanescu M, Stesmans A, Cuppens J, Bael M, Yamada H, Sato N, Verbiest T, Koeckelberghs G (2010) Macromolecules 43:2910

23. Goto H (2008) Polymer 49:3619

24. Kaneko T, Abe H, Namikoshi T, Marwanta E, Teraguchi M, Aoki T (2009) Synth Met 159:864 
25. Nakahara K, Iriyama J, Iwasa S, Suguro M, Satoh M, Cairns E (2007) J Power Sources 163:1110

26. Ikeda H (2008) J Photopolym Sci Technol 21:327

27. Okuda Y, Lakshmikantham M, Cava M (1991) J Org Chem 56:6024

28. Goto H, Koyano T, Ikeda H, Yoshizaki R, Akagi K (2004) Polymer 45:4559

29. Faulques E, Wallnöfer W, Kuzmany H (1989) J Chem Phys 90:7585

30. Zerbi G, Magnoni M C, Hoogmartens I, Kiebooms R, Carleer R, Vanderzande D, Gelan J (1995) Adv Mater 7:1027

31. Neugebauer H, Kvarnström C, Brabec C, Sariciftci N S, Kiebooms R, Wudl F, Luzzati S (1999) J Chem Phys 110:12108

32. Yoshioka N, Nishide H, Tsuchida E (1990) Mol Cryst Liq Cryst 190:45

33. Li Y, Cao Y, Gao J. Wang D, Yu G, Heeger A (1999) Synth Met 99:243

34. Bonardi L, Kanaan H, Camerel F, Jolinat P, Retailleau P, Ziessel R (2008) Adv Funct Mater 18:401

35. Scharber M, Mühlbacher D, Koppe M, Denk P, Waldauf C, Heeger A, Brabec C (2006) Adv Mater 18:789

36. Nishide H, Doi R, Oyaizu K, Tsuchida E (2001) J Org Chem 66:1680

37. Chen W, Bowmaker G, Cooney R (2002) Phys Chem Chem Phys 4:4218

38. Yoshizawa K, Tanaka K, Yamabe T (1992) J Chem Phys 96:5516 
Table 1 FT-IR and FT-Raman bands of poly1 and poly2

\begin{tabular}{|c|c|c|c|c|c|}
\hline polymer & $\begin{array}{l}\text { FT-IR } \\
\left(\mathrm{cm}^{-1}\right)\end{array}$ & $\begin{array}{c}\text { FT-Raman } \\
\left(\mathrm{cm}^{-1}\right)\end{array}$ & polymer & $\begin{array}{l}\text { FT-IR } \\
\left(\mathrm{cm}^{-1}\right)\end{array}$ & $\begin{array}{c}\text { FT-Raman } \\
\quad\left(\mathrm{cm}^{-1}\right)\end{array}$ \\
\hline \multirow[t]{17}{*}{ poly1 } & 3431 & 1464 & \multirow[t]{17}{*}{ poly2 } & 2955 & 1464 \\
\hline & 2957 & 1444 & & 2905 & 1444 \\
\hline & 2909 & 1304 & & 2865 & 1304 \\
\hline & 2858 & 1170 & & 1589 & 1170 \\
\hline & 1630 & 990 & & 1453 & 990 \\
\hline & 1588 & 446 & & 1391 & 446 \\
\hline & 1393 & 251 & & 1276 & 254 \\
\hline & 1262 & & & 1193 & \\
\hline & 1192 & & & 1146 & \\
\hline & 1144 & & & 1047 & \\
\hline & 1099 & & & 980 & \\
\hline & 1044 & & & 874 & \\
\hline & 976 & & & 843 & \\
\hline & 807 & & & 741 & \\
\hline & 743 & & & 711 & \\
\hline & 517 & & & 441 & \\
\hline & 441 & & & & \\
\hline
\end{tabular}


Table 2 Molecular weights, UV-vis optical absorption spectroscopy, and cyclic voltammetry $(\mathrm{CV})$ measurement results of poly1 and poly2

\begin{tabular}{|c|c|c|c|c|c|c|c|c|c|c|}
\hline & $M_{\mathrm{n}}^{\mathrm{a}}$ & $M_{\mathrm{w}}^{\mathrm{a}}$ & $M_{\mathrm{w}} / M_{\mathrm{n}}$ & $\begin{array}{l}\lambda_{\max } \\
(\mathrm{nm})\end{array}$ & $\begin{array}{c}E_{\mathrm{g}}(\mathrm{opt}) \\
(\mathrm{eV})\end{array}$ & $\begin{array}{c}E_{\text {ox/onset }} \\
{ }^{\mathrm{c}}(\mathrm{V})\end{array}$ & $\begin{array}{c}E_{\text {HOMO }}{ }^{d} \\
(\mathrm{eV})\end{array}$ & $\begin{array}{c}E_{\text {red/onset }}{ }^{c} \\
\text { (V) }\end{array}$ & $\begin{array}{c}E_{\text {LUMO }}{ }^{\mathrm{e}} \\
(\mathrm{eV})\end{array}$ & $\begin{array}{c}E_{\mathrm{g}}(\mathrm{CV})^{\mathrm{f}} \\
(\mathrm{eV})\end{array}$ \\
\hline poly1 & 2000 & 2980 & 1.5 & 673 & 1.32 & 0.59 & -5.34 & -1.08 & -3.67 & 1.67 \\
\hline poly2 & 1440 & 1880 & 1.3 & 642 & 1.33 & 0.58 & -5.33 & -1.11 & -3.64 & 1.69 \\
\hline
\end{tabular}

${ }^{a}$ Polystyrene standard, THF as the solvent. ${ }^{b}$ Estimated from onsets of optical absorption spectra. ${ }^{\mathrm{c}}$ Calibrated against ferrocene. ${ }^{\mathrm{d}}$ Estimated from $E_{\text {ox/onset. }}{ }^{\mathrm{e}}$ Estimated from $E_{\text {red/onset. }}{ }^{\mathrm{f}}$ Estimated from $E_{\mathrm{HOMO}}$ and $E_{\mathrm{LUMO}}$. 


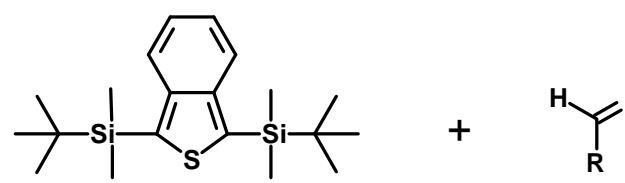

1

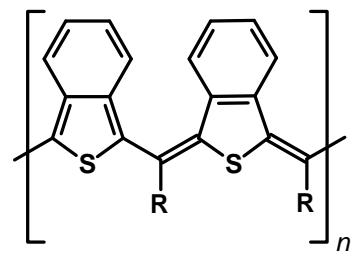

Poly1

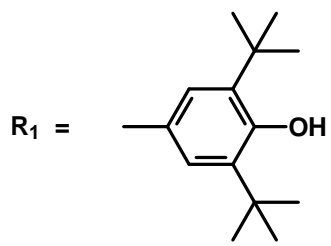

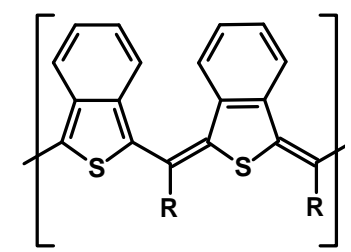

Poly1 $\left(R=R_{1}\right)$

Poly2 $\left(R=R_{2}\right)$

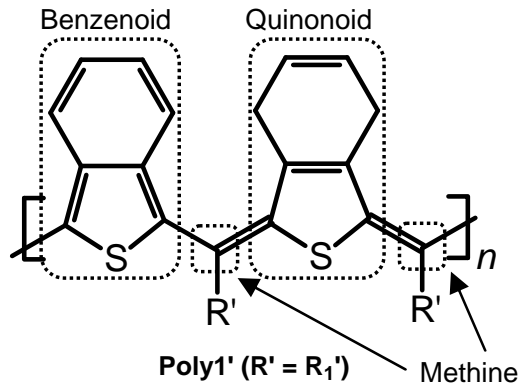

$\mathbf{R}^{\prime}{ }^{\prime}=$<smiles>Cc1cc(C(C)(C)C)c([O])c(C(C)(C)C)c1</smiles>

Scheme 1 Synthetic routes to poly(isothianaphthene methine)s 

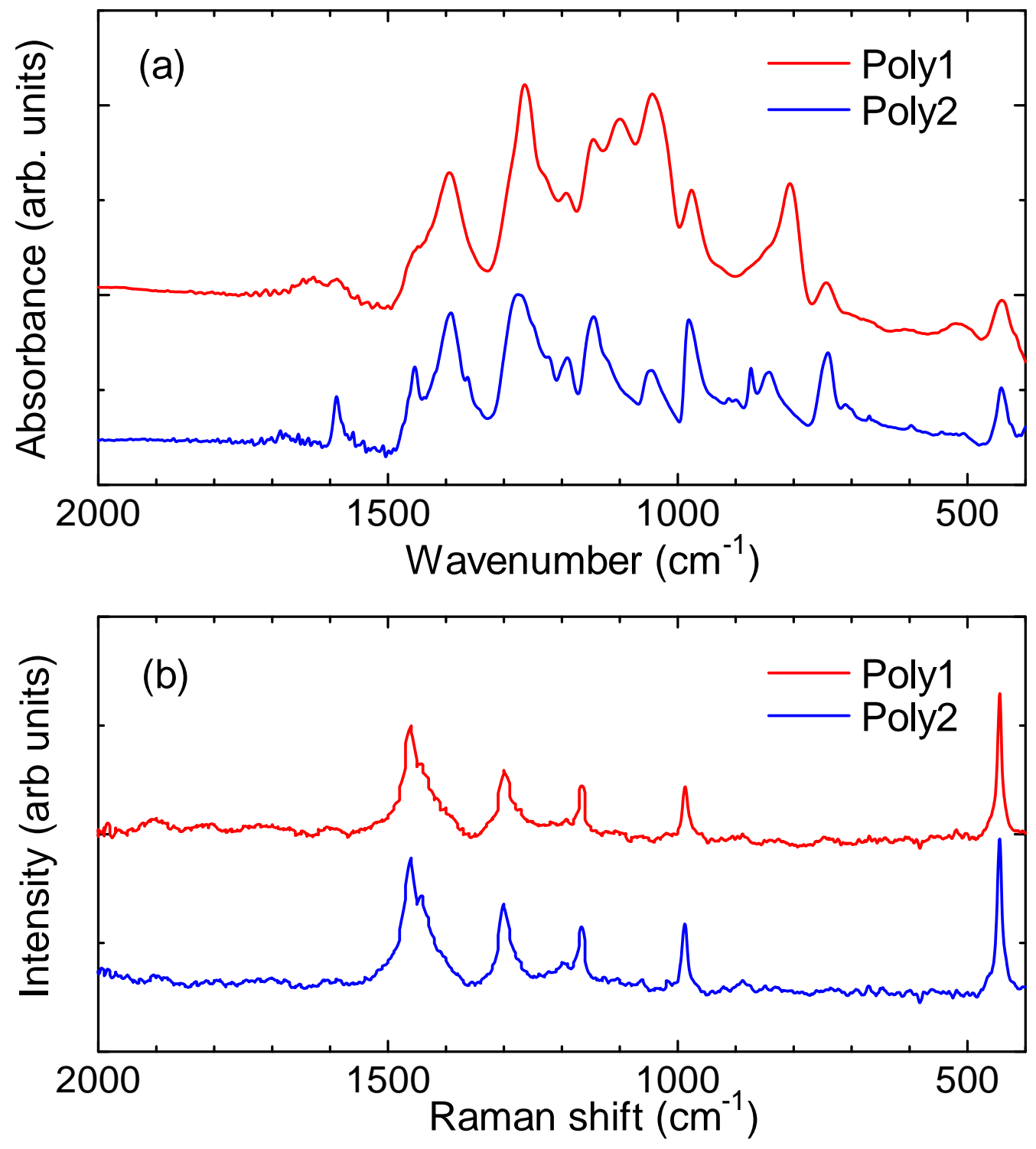

Fig. 1 FT-IR spectra (a) and FT-Raman spectra (b) of poly1 and poly2 

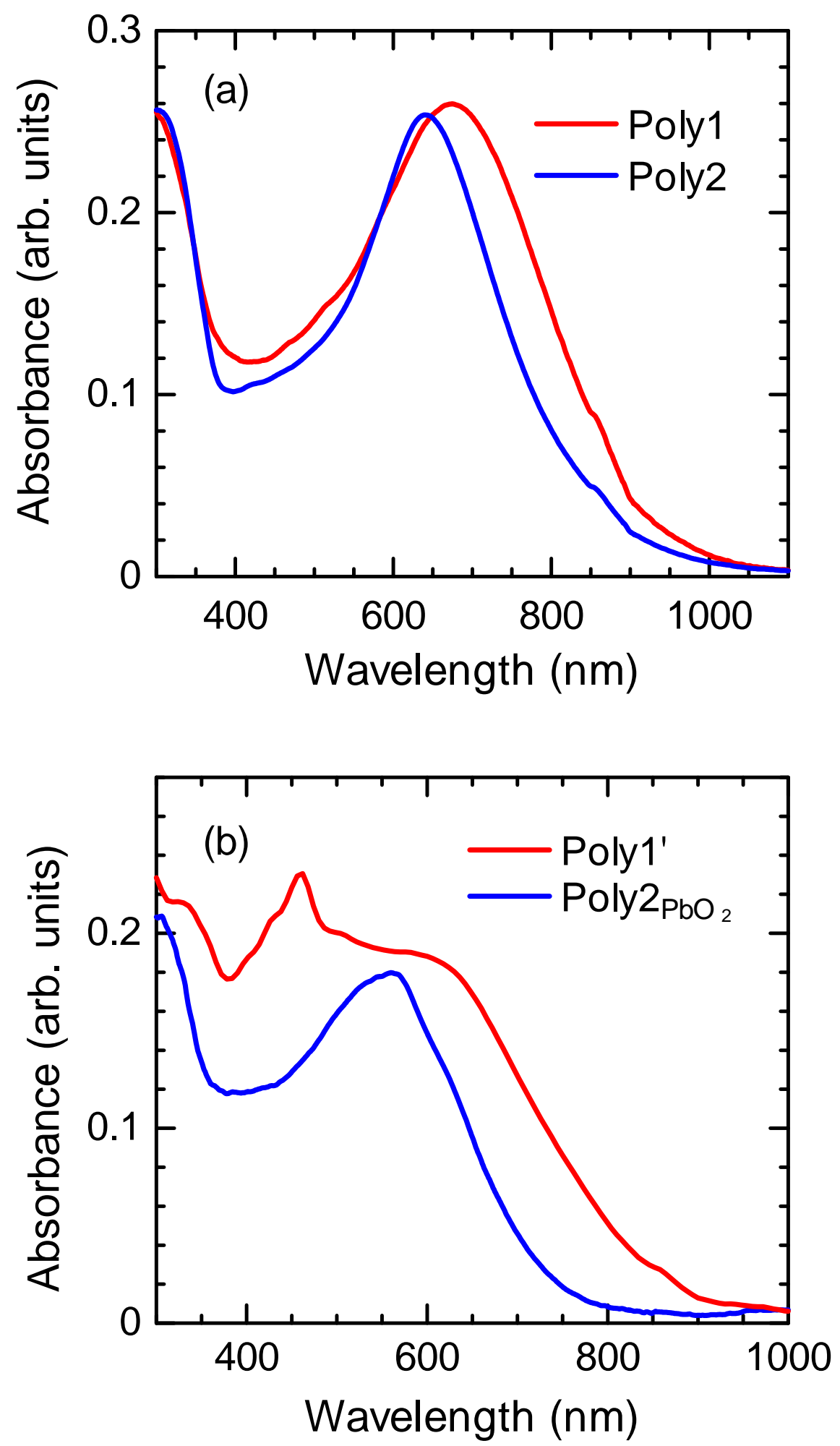

Fig. 2 (a) UV-vis absorption spectra of poly1 and poly2. (b) UV-vis absorption spectra of poly1' and poly2 after oxidation with $\mathrm{PbO}_{2}$ (poly2 ${ }_{\mathrm{PbO} 2}$ ) 


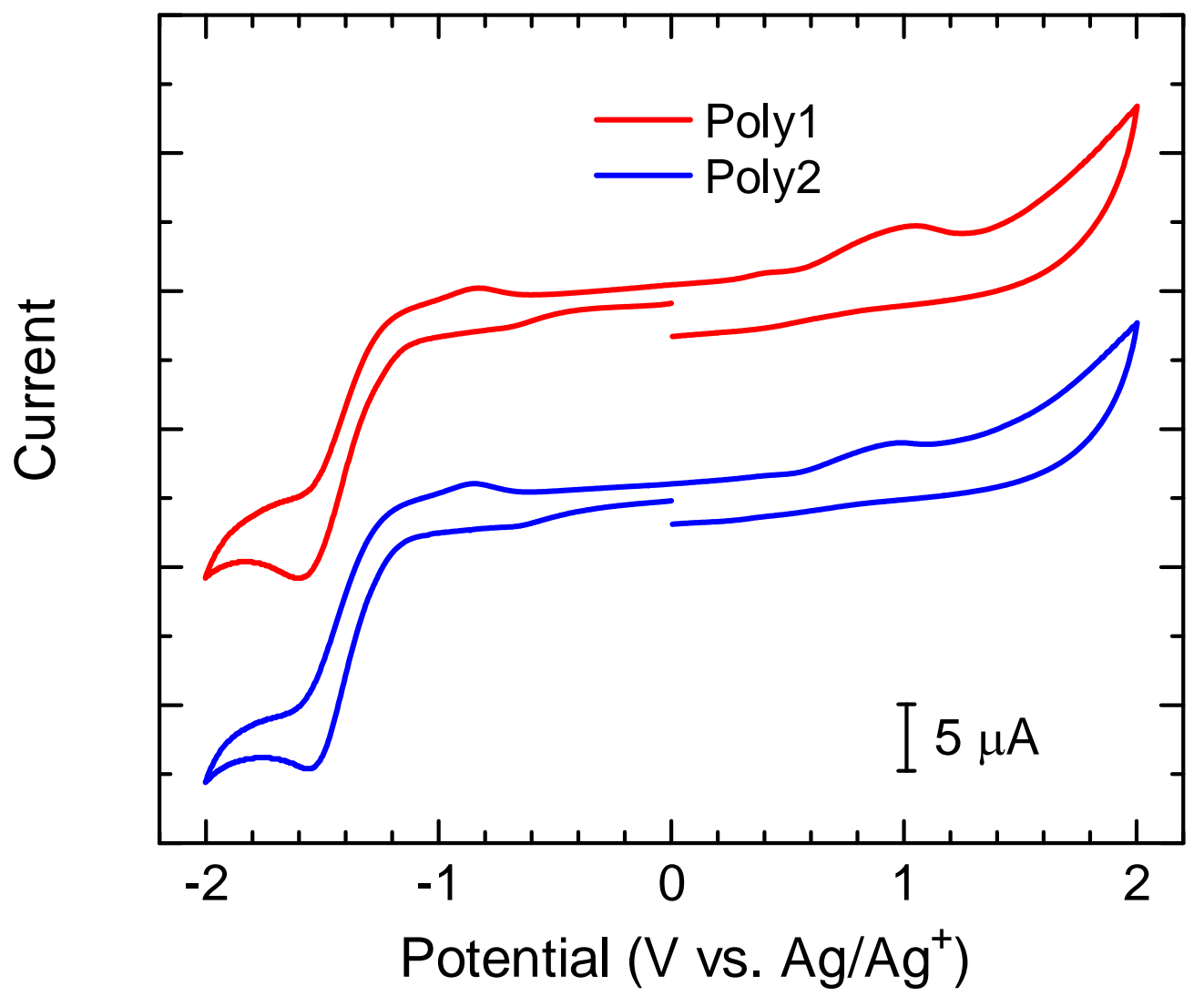

Fig. 3 Cyclic voltammograms of poly1 and poly2 cast films on a platinum working electrode 

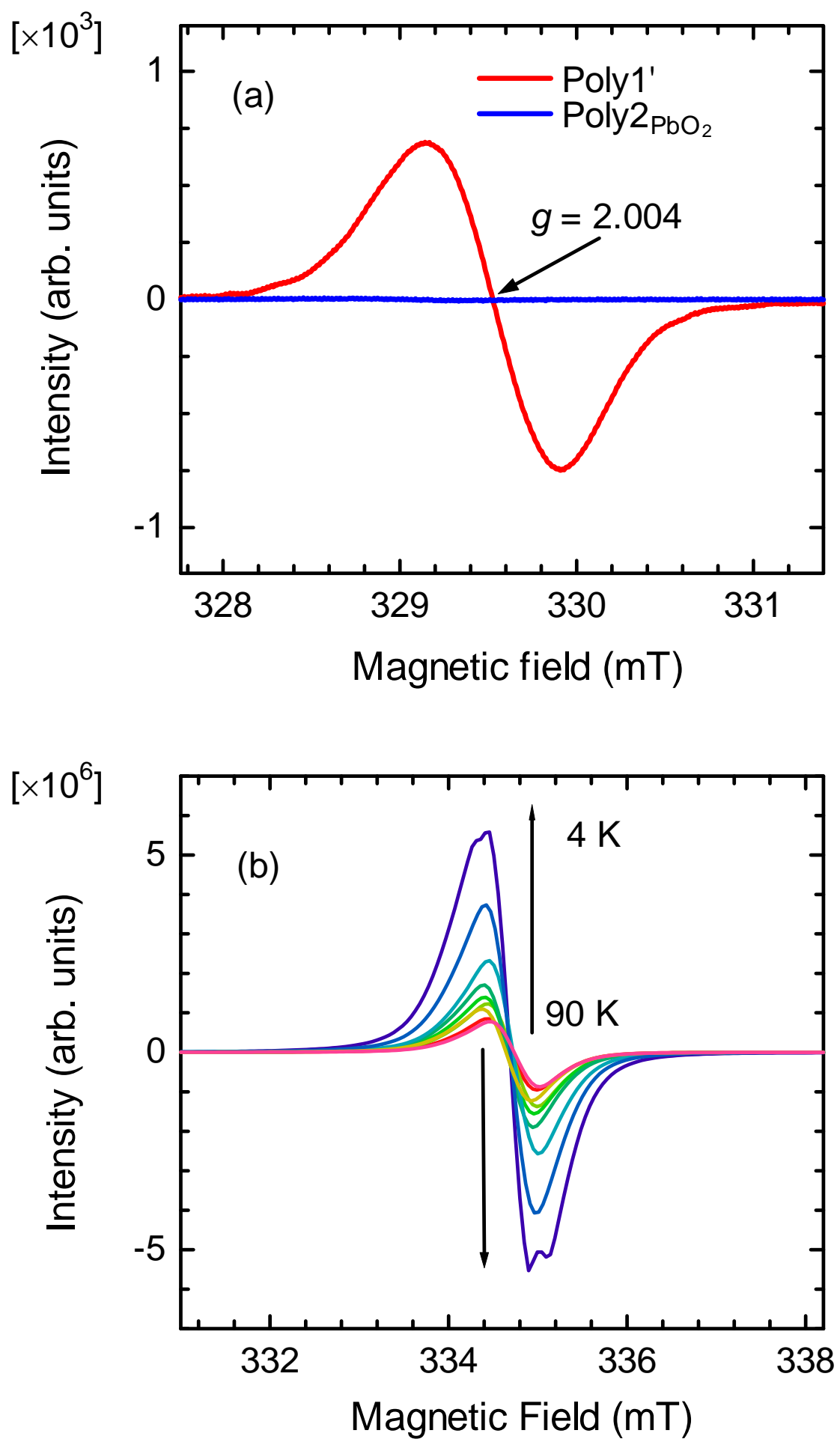

Fig. 4 (a) ESR spectra of poly1' and poly2 $\mathrm{PbO}_{2}$ at room temperature. (b) ESR spectra of poly $1^{\prime}$ at $4-90 \mathrm{~K}$ under a vacuum atmosphere 


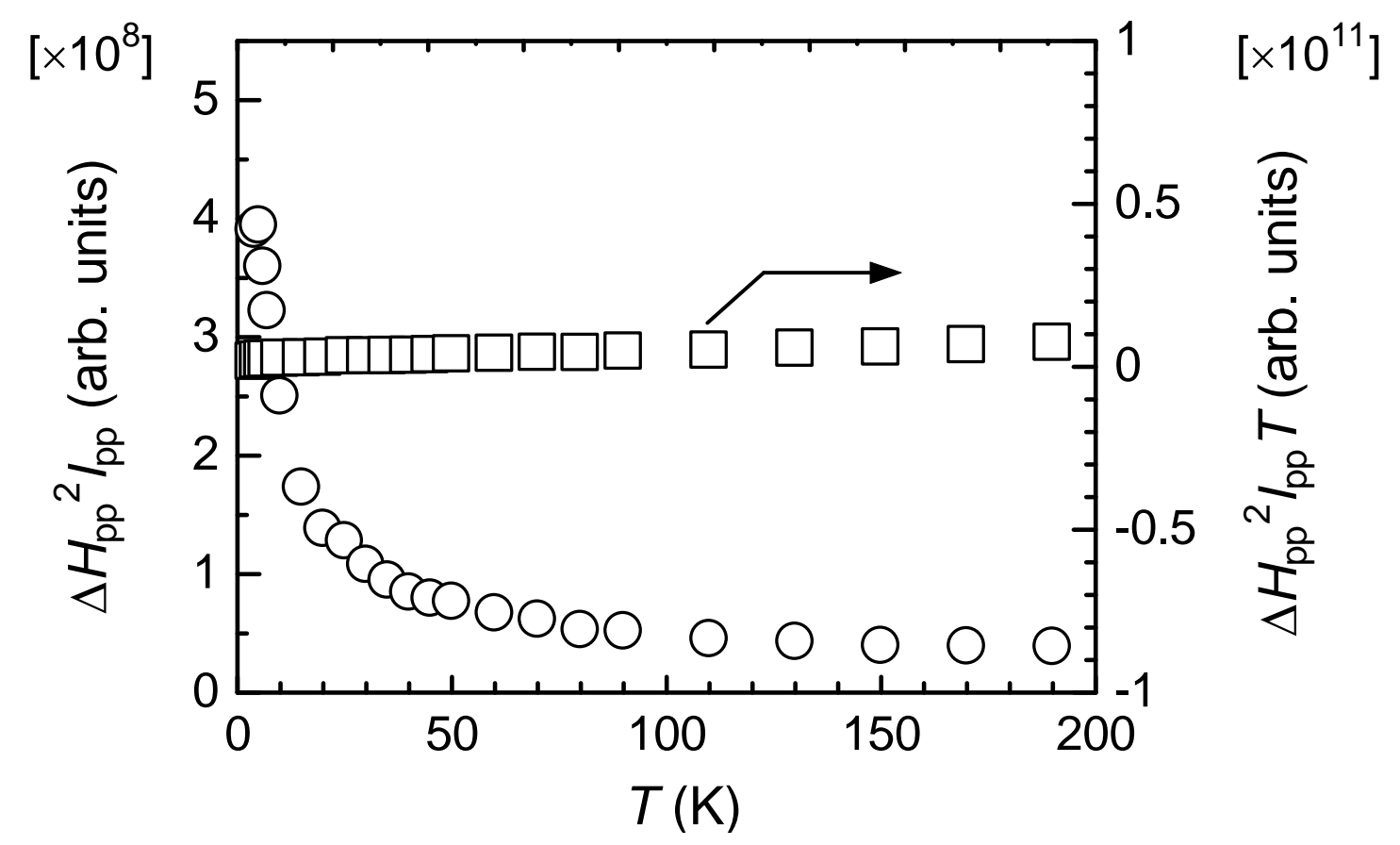

Fig. $5 \chi\left(\Delta H_{p p}{ }^{2} I_{p p}\right)$ vs. $T$ plots (circles) and $\chi T\left(\Delta H_{p p}{ }^{2} I_{p p} T\right)$ vs. $T$ plots (squares) for poly1' obtained with ESR 


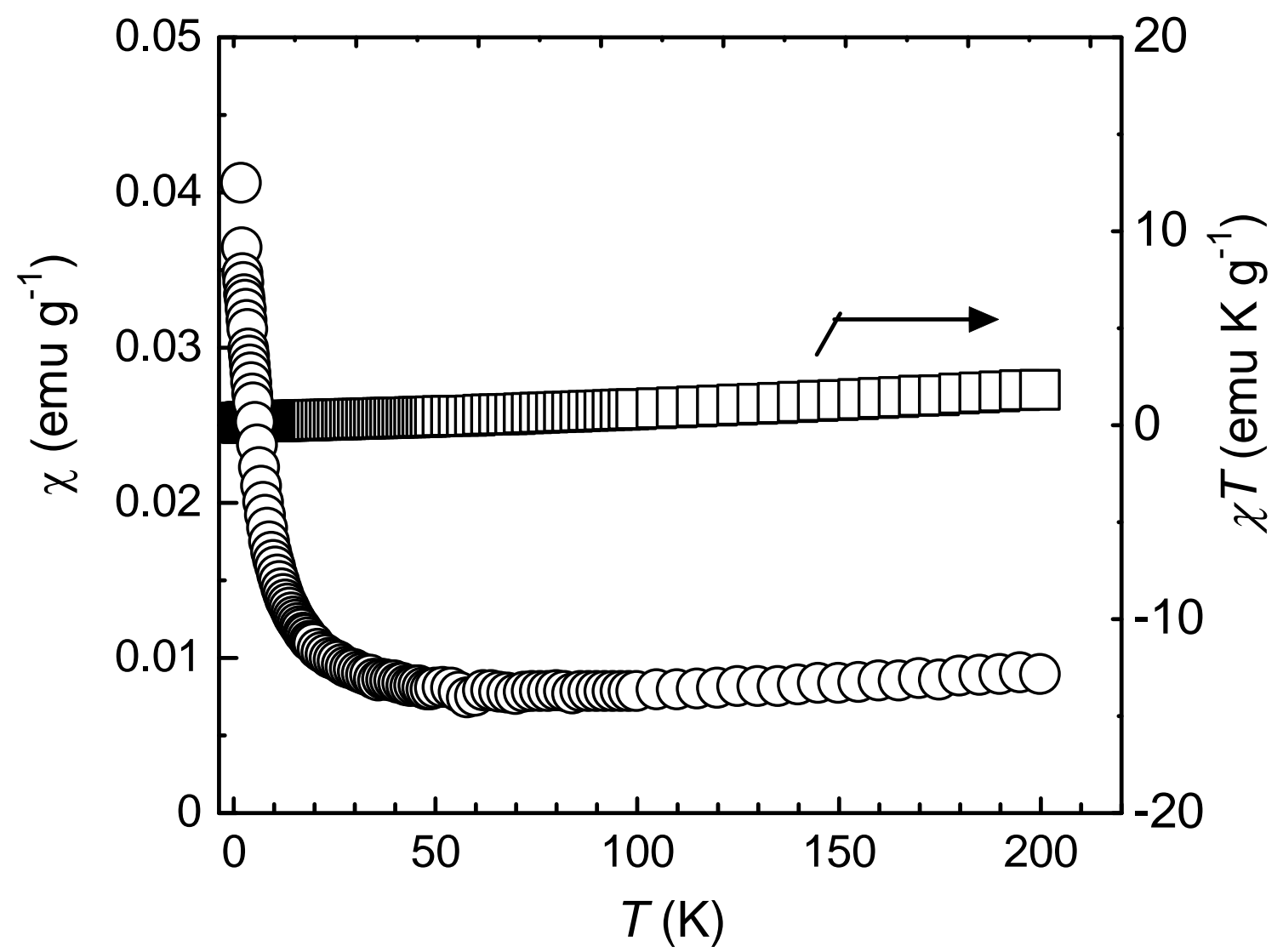

Fig. $6 \chi$ vs. $T$ plots (circles) and $\chi T$ vs. $T$ plots (squares) for poly1' obtained with SQUID (1 T) 